\title{
Medico-social Profile of Women Experiencing Menopausal Syndrome Attending a Periurban Hospital
}

\author{
S TASNIM $^{\mathrm{a}}$, FHA HOQUE ${ }^{\mathrm{b}}$, S NAZMEEN $^{\mathrm{c}}$
}

\begin{abstract}
Summary:
Women's health is a global concern now a days. Studies on issues relating to menopause is lacking Bangladesh and those been conducted mainly focus on physical and psychological symptoms around the time of menopause. This cross sectional study was done to explore the sociomedical context and nutritional characteristics of a group of women approaching menopause

A total 106 women aged 45-60 years attending Gynae outpatient department of a tertiary hospital between MarchMay, 2013 was interviewed using structured questionnaire after obtaining informed written consent. Height and weight was measured using standardized procedure. Data analysed using SPSS.

Mean age was $50.3 \pm 5.3$ years, about $75.5 \%$ were between 45-50 years, $85.1 \%$ had more than 2 children and $72.6 \%$ had history of Abortion. Mean age at menopause $44.65 \pm$ 6.4 years, range 32-58 yrs. Mean BMI was $25 \pm 4.2$ and
\end{abstract}

Introduction:

Menopausal transition is an unique stage of women's life that preceeds menopause or permanent cessation of menstruation. Average age at menopause varies across the globe, the range is normally $45-55$ years ${ }^{1}$. Premature menopause is if it occurs before age 40 and it is late menopause if the women is still menstruating at 55 years ${ }^{2}$. However, the middle aged women experience some symptoms due to declining ovarian function and are vulnerable to certain chronic diseases.

Prevalence of chronic non-communicable diseases are emerging as a challenge in most developing countries.

a. Prof. Saria Tasnim, Executive Director \& Professor of Obstetrics \& Gynaecology (Retd), Institute of child and mother health

b. Dr. FH Anamul Hoque, Assistant Professor, Gynae \& Obs, Institute of child and mother health

c. Dr. Summyia Nazmeen, Junior Consultant, Gynae \& Obs, Centre for women and Child Health

Address of Correspondence: Dr Saria Tasnim, Prof. Obs \& Gynae \& Ex Executive Director, Institute of Child and Mother Health. Matuail. Dhaka-1362, Apartment D-5. House 12. Road 126. Gulshan 1. Dhaka-1212, Phone: 00-88-8833454, mobile: 01819221096, Email: sariatasnim2007@gmail.com
43.4\% were overweight or Obese. Chronic illness like hypertension and arthritis was present in (15.09\%) and diabetes mellitus in $10.3 \%$. The family relationship with children was good in $78.09 \%$, husband was reported caring in $72.3 \%$ and $2.8 \%$ receive abusive behavior from husband. Only $8.5 \%$ were self earning, $24.5 \%$ and \& $17.9 \%$ were dependent on children and husband respectively.

With increasing life expectancy and improvements of health care services there is greater chance of survival for a women beyond menopause. Sociocultural and medical characteristics of midlife women is important to explore their specific health needs. Ensuring quality of life for this special group of women will help to better utilize their potential for development of the country.

Key words: Medico-social profile, Menopause, menopausal transition, quality of life, social context, nutrition.

(J Bangladesh Coll Phys Surg 2017; 35: 179-183)

Presence of one or more risk factors like obesity, glucose intolerance, dyslipidemia, and hypertension contributing to cardiovascular disease and type 2 diabetes are common in women above 55 years $^{3}$. Changing hormonal milieu with decreasing estrogen and alteration of its ratio with testosterone have been implicated as causes for emergence of metabolic syndrome at menopausal transition ${ }^{4}$. Epidemiological studies revealed that South Asian women, in general are prone to have metabolic syndrome at a younger age and have severe morbidity and mortality consequences as compared to Caucasians and other Asians ${ }^{5}$. Although the data on metabolic derangements in perimenopausal women are very rare in Bangladesh. Jesmin et al has found that prevalence of metabolic syndrome was $25.8 \%$ among rural women aged e" 45 years and there was higher prevalence among postmenopausal $(39.3 \%)$ as compared to premenopausal $(16.8 \%)^{6}$.

Although Menopause is a universal biological phenomenon, the individual expression of the event may be different. Differ-ences that are observed may have their ori-gins in differing genetics interacting with 
lifestyle, culture, and other factors as yet undefined ${ }^{7}$. Symptoms experienced during menopause may be influenced by social structure, cultural beliefs, life style and awareness. The symptoms are less severe in society where menopause is viewed as positive rather than negative event A cultural base of strong social bonding and higher status to elderly can ease suffering and pains of menopause and can provide a positive outlook about midlife changes ${ }^{8}$.

In Bangladesh the proportion of women of 50 years and above is increasing and life expectancy for female has reached 73.1 years $^{9}$. A considerable amount of women's life is likely to be spent as postmenopausal. Appropriate care should be available to improve the quality of life during this phase of life. However, there exists huge gap in identifying health needs of this group as special entity. Govt. health program mainly address reproductive age group (15-45 years.) and women aged 45 years and above age are mostly ignored. Provisions of health services to those people are a challenge because of lack of awareness regarding their special needs and also there is limited competency among health care providers to deal with them. In this study the social, nutritional and medical characteristics of a group of women approaching menopause and beyond were explored to identify the type of services they would need.

\section{Method:}

This descriptive study was carried in an outpatient Gynecology department of a tertiary hospital located in a periurban area during March-May, 2013. Convenient sampling was done among the women aged $45-60$ Years attending Gynae outpatient department as patient or attendant of antenatal patients. Women who were seriously ill due to reasons associated or not associated with menopause were excluded from the study. Data was collected from total 106 women by doctors specially trained for the purpose using structured questionnaire. Height and weight was measured using standardized procedure and BMI was calculated. Institutional ethical committee approved the study \& informed consent was taken from the respondents before data collection.

\section{Results:}

Mean age was $50.3 \pm 5.3$ years, $75.5 \%$ were between 45-50 years. (Table I). Mean age at first marriage was $15.2 \pm 34$ years and $46.7 \%$ were married before 15 years, about $81.1 \%$ had more than 2 children (Table II). Mean age at menopause was $44.65 \pm 6.4$. Mean wt was 56.08 \pm 10.09 , (range $38-82 \mathrm{~kg}$ ), Mean Height was $149.5 \pm$ 5.6, (range 137-162 cm), Mean BMI was $25 \pm 4.2$ (range 16.4-35.7) and 43.4\% were overweight or obese (Table III). Regarding chronic illness most common were hypertension and arthritis (15.09\%), next was diabetes mellitus (Table IV).

Table-I

Socio-demographic Characteristics

\begin{tabular}{lcc} 
Variable & Frequency & Percentage \\
\hline Age & & \\
45 -50 years & 80 & 75.5 \\
51-55 years & 8 & 7.5 \\
$\geq 56$ & 18 & 17.0 \\
Monthly Family Income & & \\
$<10,000$ taka & 64 & 62.4 \\
$10001-20000$ taka & 24 & 23.0 \\
$>20000$ taka & 14 & 14.6 \\
\hline
\end{tabular}

Table-II

\begin{tabular}{lcc}
\multicolumn{3}{c}{ Distribution according to Obstetric history } \\
& Frequency & Percentage \\
\hline Age at first marriage & & \\
$<15 \mathrm{yrs}$ & 49 & 46.7 \\
15-20yrs & 49 & 46.7 \\
>21yrs & 7 & 6.7 \\
unmarried & 1 & 0.9 \\
Parity & & \\
Nulliparous & 5 & 4.7 \\
1-2 Child & 15 & 14.1 \\
$\geq 3$ & 86 & 81.1 \\
\hline
\end{tabular}

Table-III

\begin{tabular}{lcc}
\multicolumn{3}{c}{ Distribution according to BMI } \\
& Frequency & Percentage \\
\hline$<18.5$ & 4 & 3.8 \\
$18.5-24.9$ & 56 & 52.8 \\
$25-29.9$ & 34 & 32.1 \\
Equal or $>30$ & 12 & 11.3 \\
\hline Total & $106^{6}$ & 100 \\
\hline
\end{tabular}


Table-IV

\begin{tabular}{lcc}
\multicolumn{3}{c}{ Distribution according to chronic Disease, $n=106$} \\
& Frequency & Percentage \\
\hline Diabetes & 11 & 10.3 \\
Hypertension & 16 & 15.09 \\
Asthma & 10 & 9.4 \\
Arthritis & 16 & 15.09 \\
Peptic Ulcer Disease & 4 & 3.7 \\
Vision problem & 7 & 6.6 \\
No response & 36 & 33.9 \\
Others (Body achae, & 6 & 5.6 \\
muscle pain) & & \\
& $106^{\circ}$ & 100 \\
\hline
\end{tabular}

The family relationship with children was good among majority of women $(78.09 \%)$, husbands were reported to be caring by $72.3 \%$ and $9.5 \%$ said that husband did not take care and rather they were abusive $(2.83 \%)$ (Table V). Regarding economic dependency $8.5 \%$ were not dependent, $24.5 \%$ were dependent on children and in $19.8 \%$ both husband and wife are earning members of the family (Table VI).

\section{Table-V}

Distribution according to family relation, $n=106$

\begin{tabular}{lcc} 
& Frequency & Percentage \\
\hline Husband take care & 76 & 72.3 \\
Husband does not take care & 10 & 9.5 \\
Husband abusive & 3 & 2.83 \\
Good relation - children & 82 & 78.09 \\
Children does not take care & 4 & 3.80 \\
\hline
\end{tabular}

Table-VI

\begin{tabular}{lcc}
\multicolumn{3}{c}{ Distribution according to Economic dependency } \\
& Frequency & Percentage \\
\hline Not Dependent & 9 & 8.5 \\
Spouse & 19 & 17.9 \\
Child & 26 & 24.5 \\
Self earning \& Spouse & 21 & 19.8 \\
Self earning \& Child & 9 & 8.5 \\
Spouse \& Child & 17 & 1.6 \\
Self earning, Spouse \& Child & 5 & 4.7 \\
& 106 & 100 \\
\hline
\end{tabular}

\section{Discussion:}

The average age at menopause in western countries has risen by 5 years in the last century; this change probably reflects a general improvement in health and vigor in the community and a determination of women to stay young ${ }^{2}$. Studies conducted in Ghana reported the mean age of onset of menopause to be $48 \pm 2.9$ years ${ }^{10}$.In a study from Nigeria reported that the mean menopausal age was $44.8 \pm 2.6 \mathrm{yrs}^{11}$, and it was reported $47.44 \mathrm{yrs}$ from Iraq ${ }^{12}$ and $45.75 \pm 4.7$ yrs from Turkey ${ }^{13}$.

Mean age of menopause in different studies from Bangladesh was reported 51.4 years $\pm 2.11^{14}$, and 47.9 +4.5 years ${ }^{15}$ which are higher than current study (44.6 \pm 6.4$)$. In an earlier study from rural area. median age at menopause was reported to be 43.6 years ${ }^{16}$ .Murphy et al found that ages at menopause were significantly earlier among Bangladeshi sedentees and immigrants compared to Londoners of European origin $^{17}$.

In south Asia, reported mean $\&$ median ages at menopause are often much lower ${ }^{17}$. In India the age at menopause has been variously calculated as 48.7 years $^{18}, 46.8$ years $^{19}$ and 47.7 years respectively ${ }^{20}$. Earlier onset of menopause is associated with malnourished women, lower education, low socioeconomic status, smoking and if the women herself was been a growth restricted $\&$ low birth weight baby ${ }^{21}$. A late menopause is associated with high parity, prior use of oral contraception, obesity, consumption of alcohol, uterine fibroids \& endometrial carcinoma ${ }^{21}$. In the current study about $40 \%$ had premature menopause which is consistent with study of Nahar et al $(40 \%)^{15}$. Mostafa from Iraq reported premature menopause in $23.6 \%$ and in a rural area of India prevalence of premature menopause was reported $16 \%{ }^{22}$. In the current study $91.9 \%$ had natural menopause and $8.06 \%$ had surgical menopause which is comparable to Tanira's study which was 94.3 and 5.6\% respectively ${ }^{23}$.

Menopause transition is often associated - changes in body composition. In a study from Ghana menopause was associated with increased accumulation of fat leading to an increase in weight ${ }^{10}$. This is consistent current study which shows a greater percentage of the participants were overweight. Most menopausal women are vulnerable to changes in nutritional status due to hormonal changes, bad eating habits or faulty 
lifestyles ${ }^{24}$. An unbalanced diet, low physical activities and emotional stress can intensify symptoms of menopause ${ }^{24}$.

In a study from Bosnia, $12.33 \%$ of postmenopausal woman (age 45-55 Years) was within normal range of nutrition while $87 \%$ were overweight and obese. The appearance of menopausal symptoms everyday was found to be linked to higher BMI ${ }^{24}$. Study from United States of America revealed that adult American women tend to gain weight with age and many women report that their weight gain started around the time of onset of menopause ${ }^{10}$. As women's age advances, there are changes in body composition that include losses in bone mineral, body cell mass and increase in total body fat, visceral fat and extra cellular fluid and it appears that these body composition changes begin or accelerate during the menopausal years ${ }^{10}$. However study in a rural area of Bangladesh reported that around 52.9\% postmenopausal women had BMI below 18.5 and 39\% were between $18.5-23.49^{15}$.

Hypertension and DM were common medical disorders in peri \& post menopausal women in this study. Nisar et al reported that $25 \%$ of postmenopausal women were hypertensive and $20.85 \%$ were diabetic ${ }^{25}$. Roshan reported that $31.5 \%$ were hypertensive and $5 \%$ were diabetic $^{26}$. In a study from Bangladesh mean BMI was found $24.3 \pm 4.4,13 \%$ had heart disease and $9 \%$ had type 2 Diabetes. However, routine screening for this age group and counseling for quality of life may be helpful for early detection of metabolic disorders and prevention of complications ${ }^{27}$.

Economic dependency is a determining factor for health seeking of menopausal women. In the current study a good proportion of women had contribution to family earning $\&$ only a quarter was dependent on children. In a study from rural India most common mode of dependency was on children (42.9\%) and $28.6 \%$ was self dependent ${ }^{20}$. In spite of growing urbanization and rearing of children in a nuclear family living within an extended family is still a social norm. Some women mentioned that they are looked after by grand children.

Family relationship with husband and children was reported to be positive in most cases and some were looked after by their grand children. This may be a reflection of traditional social custom of valuing elderly people on their own accord and to carry on family responsibilities through generations.

\section{Conclusion:}

Menopause is a unique transition of women's life and has concerns different from those of reproductive life and old age. Women reported to attain menopause quite early. Family relationship with husband and children was reported to be good. Significant proportion of women was overweight which may be due to hormonal changes. Chronic diseases like Hypertension, Diabetes were quite common. Health needs of midlife women are yet to be explored with caution. Creating awareness about consequences of menopause, life style modification for coping with changes, screening for disease and provision of services to improve the quality of life would contribute to keep them healthy and active for longer time.

\section{References}

1. World Health Organization. Research on menopause in the 1990s: report of WHO scientific group. WHO Technical Report Series 866. Geneva, CH: World Health Organization; 1996.

2. Jeffcoate's principles of Gynaecology. Pratap kumar and Narendra Malhotra (Eds). Seventh edition. 2008. Jaypee Medical Publishers. New Delhi

3. Mottillo S, Filion KB, Genest J, Joseph L, Pilote L, Poirier P, Rinfret S, Schiffrin EL, Eisenberg MJ: The metabolic syndrome and cardiovascular risk: a systematic review and meta-analysis. J Am Coll Cardiol 2010, 56:1113-1132.

4. Janssen I, Powell LH, Crawford S, Lasley B, Sutton-Tyrrell K: Menopause and the metabolic syndrome: the Study of Women's Health Across the Nation. Arch Intern Med 2008, 168:1568-1575.

5. Misra A, Khurana L: The metabolic syndrome in South Asians:epidemiology, determinants, and prevention. Metab Syndr Relat Disord 2009, 7:497-514.

6. Subrina Jesmin, AM Shahidul Islam, Shamima Akter, et.al Metabolic syndrome among pre- and post-menopausal rural women in Bangladesh: result from a population-based study BMC Research Notes 2013, 6:157 http:// www.biomedcentral.com/1756-0500/6/157

7. Loh, F.H. Menopausal Medicine: For Clinicians Who Provide Care for Women Menopause and $\mathrm{t} /$ he Asian Woman. American Society for Reproductive Medicine 2007 ; 15: 6-10.

8. Aarti Kaulagekar. Menopause and Femininity: Qualitative Enquiry into Menopause of Urban Women from Pune, Maharashta. Antropologist 2010; 12 (1): 23-26 .

9. Bangladesh Buraeu of Statistics 2015 
10. Jacob Setorglo, Rebecca S. Keddey, Isaac Agbemafle, et.al. Determinants of Menopausal Symptoms among Ghanaian Women Current Research Journal of Biological Sciences 4(4): 507-512, 2012 ISSN: 2041-0778

11. Ande AB, Omu OP, Ande OO, Olagbuji NB. Features and perceptions of menopausal women in Benin City, Nigeria. Ann Afr Med. 2011 ;10(4):300-4. doi: 10.4103/15963519.87048 .

12. Mustafa G N, Sabir J M (2012): Perceptions and experience regarding menopause among menopausal women attending teaching hospitals in Erbil city, Global journal of Health Science; 4 (3): 170-178

13. Yangin HB, Sözer GA, Sengün N, Kukulu K. The relationship between depression and sexual function in menopause period. Maturitas. 2008; 61(3):233-7. doi: 10.1016/ j.maturitas.2008.09.004. Epub 2008

14. Rahman S, Salehin F, Iqbal A. Menopausal symptoms assessment among middle age women in Kushtia, Bangladesh. BMC Res Notes 2011; 4: 188.

15. Shamsun Nahar, Sadiqa Tahera Khanam, Mamunur Rashid, Rukia Khatun, Yasmin Rahman, Humayun Kabir. Menopause in rural Bangladeshi women.December 2006.

16. Karim A, Chowdhury AKMA, Kabir M. 1985. Nutritional status and age at secondary sterility in rural Bangladesh. J Biosoc Sci 17:497-502.

17. Murphy L, Sievert L, Begum K, Sharmeen T, Puleo E, Chowdhury O, Muttukrishna S, Bentley G. Life course effects on age at menopause among Bangladeshi sedentees and migrants to the UK. Am J Hum Biol. 2013;25(1):83-93. doi: 10.1002/ajhb.22345. Epub 2012 Nov 22.

18. Bairy L, Adiga S, Bhat P, Bhat R., Prevalence of menopausal symptoms and quality of life after menopause in women from South India, Aust N Z J Obstet Gynaecol., 2009, Feb 49(1):106-109

19. Kapur P, Sinha B, Pereira B. 2009. Measuring climacteric symptoms and age at natural menopause in an Indian population using the Greene Climacteric Scale. Menopause 16: Mar-Apr; 16(2):378-84.

20. Donald Christian1, Manish Kathad1, Bharat Bhavsar. Sociodemographic characteristics of postmenopausal women of rural area of Vadodara district, Gujarat. National journal of community Medicine 2011; 2 (3): 419-422

21. Suchitra Pandit, Shashikant umbardand, vijoy C powar, Prachi Bhikaji Shitut Menopause: A phase in women's life. In Pankas Desai, Narendra Malhotra, Duru shah (eds). Principles \& Practice of obstetrics \& Gynaecology for post graduates. Third edition. 2008 Jaypee publishers New Delhi

22. Akanksha Singh and Shishir Kumar Pradhan Menopausal symptoms of postmenopausal women in a rural community of Delhi, India: A cross-sectional study. J Midlife Health. 2014 Apr-Jun; 5(2): 62-67. doi: 10.4103/0976-7800.133989

23. Tanira S, Wazed F, Sultana A, Amin R, Sultana K, Ahmad S (2009). Knowledge, attitude and experience of Menopause an urban based study in Bangladesh. J Dhaka Med Coll; 18(1): 33-36.

24. Samir Tursunovi, Midhat Jaši, Azijada Beganli Nadia Hot. Nutritional status and dietary habits of menopausal women. Food in health and disease, scientific-professional journal of nutrition and dietetics (2014) 3 (2) 116-125

25. Nisar Nusrat, Zehra Nishat, Haider Gulfareen, Munir Aftab, Naeem Asia. Knowledge, attitude and experience of menopause. J Ayub Med Coll Abottabad 2008;20(1): 56-59

26. Qazi RA. Age pattern of the menopause, climactric symptoms and associated problems among the urban population of Hyderabad, Pakistan. J Coll Physicians Surg Pak 2006; 16 (11): 700-703.

27. Kawsar Ahmed, Papia Jahan, Israt Nadia, Farzana Ahmed, Abdullah-Al-Emran. Assessment of Menopausal Symptoms among Early and Late Menopausal Midlife Bangladeshi Women and Their Impact on the Quality of Life. J Menopausal Med 2016;22:39-46). 